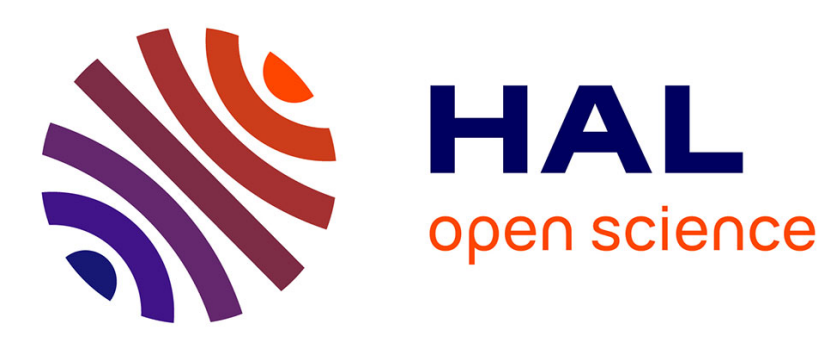

\title{
Campbell Diagram Computation for a Drillstring Immersed in Curved Wells
}

Khac-Long Nguyen, Quang-Thinh Tran, Marie-Ange Andrianoely, Lionel Manin, Régis Dufour, Stephane Menand, Mohamed Mahjoub

\section{To cite this version:}

Khac-Long Nguyen, Quang-Thinh Tran, Marie-Ange Andrianoely, Lionel Manin, Régis Dufour, et al.. Campbell Diagram Computation for a Drillstring Immersed in Curved Wells. Journal of Vibration and Acoustics, 2019, 141 (4), pp.041009. 10.1115/1.4042933 . hal-02119502

\section{HAL Id: hal-02119502 \\ https://hal.science/hal-02119502}

Submitted on 27 May 2019

HAL is a multi-disciplinary open access archive for the deposit and dissemination of scientific research documents, whether they are published or not. The documents may come from teaching and research institutions in France or abroad, or from public or private research centers.
L'archive ouverte pluridisciplinaire HAL, est destinée au dépôt et à la diffusion de documents scientifiques de niveau recherche, publiés ou non, émanant des établissements d'enseignement et de recherche français ou étrangers, des laboratoires publics ou privés. 


\title{
Campbell diagram computation for a drillstring immersed in curved wells
}

\author{
Khac-Long Nguyen* \\ Quang-Thinh Tran \\ Marie-Ange Andrianoely \\ Lionel Manin \\ Régis Dufour \\ Univ. Lyon, INSA-Lyon, \\ CNRS UMR5259, LaMCoS, \\ F-69621 France \\ Email: khac-long.nguyen@insa-lyon.fr \\ Stéphane Menand \\ Mohamed Mahjoub \\ DrillScan \\ Villeurbanne, F-69100, France
}

\begin{abstract}
The drilling operations use a rotary slender structure introduced inside the drill well. The nonlinear dynamics with bit-bouncing, stick-slip phenomena and pulsating mud flow may yield the premature wear and damage of drilling equipment and should be investigated to improve the reliability of drilling operations. This work presents the beam element formulation to model the drilling nonlinear dynamics. The well-pipes contacts are modeled by the radial elastic stops. The fluid-structure interactions are considered. The first step consists in computing the static position of structure to determine the contact points and calculate the pre-loaded state. These results are then considered to calculate the Campbell diagram. The potential unstable speeds of rotation are identified. The results show that the modal coupling phenomena strongly occur for the $3 D$ well. The well-pipes contacts modify the modes in rotation and the rotating fluid induces a strong deviation of the flexural mode curves.
\end{abstract}

\section{Nomenclature}

$\alpha, f \quad$ Real and imaginary parts of eigenvalue of the modes in rotation

$\delta, \dot{\delta} \quad$ Total FE displacement and velocity vectors

$\delta^{e}, \dot{\delta}^{e}, \ddot{\delta}^{e} \quad$ Elementary FE displacement, velocity and acceleration vectors

$\Phi \quad$ Projection matrix of the modal basis

$\Phi_{j}, \omega_{j} \quad$ Eigenvectors and eigenvalues of the modal basis

${ }^{*}$ Corresponding author. $\dot{u}, \dot{v}, \dot{\theta}_{z} \quad$ Two lateral velocities in $x, y$ directions and torsional velocity in $z$ direction.

$\mu_{s}, \mu_{d}, v_{r} \quad$ Static, dynamic friction coefficients and regularized coefficient of the friction function

$\Omega \quad$ Speed of rotation

$\vec{F}_{c n s} \quad$ FE vector of static normal contact force at one beam node

$\vec{F}_{c n} \quad$ Dynamics normal contact force at one beam node

$\vec{F}_{c t s}, \vec{T}_{c t s}$ FE vectors of static tangential friction force and torque at one beam node

$\vec{F}_{c t}, \vec{T}_{c t}$ Dynamics tangential friction force and torque at one beam node

$\partial \mathbf{F}_{c s} / \partial \delta \quad$ Total Jacobian matrix of $\mathbf{F}_{c s}$

$\rho, E, v \quad$ Mass density, Young modulus, Poisson ratio of drillstring

$\mathbf{c}_{\eta}, \mathbf{c}_{\eta, j}, \eta$ Modal viscous damping matrix, its diagonal terms and kinematic viscous coefficient of fluid

$\mathbf{C}_{a c}^{e}, \mathbf{C}_{a c} \quad$ Elementary and total matrices representing the gyroscopic effect

$\mathbf{C}_{a d}, c_{M}, c_{K}$ Rayleigh damping matrix and its two characteristic coefficients

$\mathbf{F}_{i}^{e}, \mathbf{F}_{f}^{e}, \mathbf{F}_{f e}^{e}$ Elementary FE vectors of the inertial and friction effects of outer fluid and their total effect

$\mathbf{F}_{s} \quad$ FE vector of exterior static loads (gravity, buoyancy forces, Weight-on-Bit, Torque-on-Bit)

$\mathbf{F}_{c s}, \mathbf{F}_{c n s} \quad \mathrm{FE}$ vectors of static contact forces and its normal component

$\mathbf{F}_{c t s}, \mathbf{T}_{c t s} \quad$ FE vectors of tangential friction force and torque 
$\mathbf{J}_{i, i=1 . . P} \quad$ Jacobian matrix of the static contact force at one node

$\mathbf{K}_{f e}^{e}, \mathbf{K}_{f e} \quad$ Elementary and total stiffness matrices of outer fluid effects

$\mathbf{M}, \mathbf{C}, \mathbf{K}$ Total mass, damping, stiffness matrices of the whole drilling system

$\mathbf{m}, \mathbf{c}, \mathbf{k}$ Mass, damping, stiffness matrices reduced by the modal basis technique

$\mathbf{M}^{e}, \mathbf{K}^{e} \quad$ Elementary mass and stiffness matrices

$\mathbf{M}_{f e}, \mathbf{C}_{f e}$ Total mass and damping matrices of outer fluid effects

$\mathbf{M}_{f e}^{e}, \mathbf{C}_{f e}^{e} \quad$ Elementary mass and damping matrices of outer fluid effects

$\mathbf{M}_{f i}^{e}, \mathbf{M}_{f i} \quad$ Elementary and total mass matrices of the inertial effect of the inner fluid

$\theta_{x}, \theta_{y}, \theta_{z} \quad$ Two lateral rotations around $x, y$ directions and one torsional angle around $z$ direction.

$E_{c a}, E_{d a} \quad$ Total kinetic and strain energies of the drillstring $E_{c a}^{e}, E_{d a}^{e} \quad$ Elementary kinetic and strain energies of the drillstring

$F_{a}^{e}, T_{a}^{e} \quad$ Elementary axial forces and torques

$G, \dot{G}$ Penetration and penetration velocity of beam cross-section in the well

$j_{0}, \lambda_{k}, \lambda_{c}$ Radial clearance, two regularized parameters of $K_{c}, C_{c}$

$K_{c}, C_{c} \quad$ Dynamics contact stiffness, damping functions

$L, l \quad$ Total drillstring length and beam element length

$m_{a}, \rho_{f}, f_{f}$ Added mass, mass density and tangential friction coefficient of the outer fluid

$N_{i, i=1 . .6} \quad$ Six shape functions

$P \quad$ Node number

$r, k_{c}, c_{c} \quad$ Radial displacement, nominal contact stiffness and damping

$R_{e} \quad$ Outer radius of one beam cross-section

$r_{k}, \mathbf{X}_{k}, \mathbf{q}_{k}$ Eigenvalues, total eigenvectors and reduced eogenvectors of the modes in rotation

$R_{f e}, R_{f i} \quad$ Outer and inner radii of the annular space

$S, I_{p} \quad$ Beam cross-section area, polar moment of inertia around the $z$-axis

$S_{F}, S_{T}, S_{L}$ Three indicators of like-flexural, like-torsional, like-longitudinal vibrations of modes in rotation

$u, v, w \quad$ Two lateral displacements in $x, y$ directions and one axial displacement in $z$ direction.

$v_{g}, \mu \quad$ Sliding velocity and contact friction function

\section{Introduction}

The drilling structure for oil or geothermic extraction is a long and slender structure including mainly the steel drill-pipes and a bottom-hole assembly (BHA) (see Figure 1). Drill-pipes are tubes of a typical length about 9 $\mathrm{m}$ and screwed to each other by the tooljoints. The BHA contains the drill-collars, some stabilizers and one drill-bit. These extra heavy pipes of BHA insures the transmission of Weight-On-Bit (WOB), facilitates the control of the structure dynamic behavior and the drilling direction. The drilling assembly rotates in a well bore of several kilometers length, whose top part is protected with steel tube casings. The drilling fluid is a water-based or oil-based fluid, circulates downward in the pipes and then travels back to the surface in the well-pipes annular space. Thus the rock debris evacuation, the cooling down of the tool, the lubrication of the rotating string and the dynamic stability of the system are insured.

The drilling process induces nonlinear dynamic phenomena [1] due to the bit-rock and well-pipes contacts with stick-slip phenomena [2-4] and the fluid-structure interaction. Multiple vibrations coupling axial, torsional and lateral motions may yield dangerous damages of drilling structure [5]. A thorough study of the structure dynamics is necessary to avoid the harmful vibrations and improve the drilling process stability.

In order to control the vibrations of a drilling structure, the time evolution of nonlinear dynamics has been recently modeled by many numerical studies. Christoufou et al. [6] were focused on analyzing the axial and transverse vibrations of a rotating BHA. Ritto et al. [7] used the non-parametric approach to take into account the model uncertainties in the bit-rock interaction, the fluid-structure interaction and the impact forces. Liu [8], Gupta [9], Wiercigroch [10] and their co-authors proposed the lumped parameter models with two degrees of freedom (dofs) to study the axial-torsional vibration coupling for the vertical wells or drillstrings. Kreuzer et al. [11] have conducted an academic but representative experiment and analyzed the results by considering a simple model based on few dofs. Liao et al. [12] also developed a four-dof model to study the bending and torsional dynamics of drillstrings. The finite element method has been widely implemented for modeling the dynamic behavior of drilling assembly in horizontal wells $[13,14]$ and in curved wells $[15,16]$. A dynamic model [17] based on the Timoshenko beams has been developed to analyze the suppression of lateral and torsional vibrations of drillstring by using the impact and torsional dampers. Recently, Hosseinzadeh et al. [18] presented a finite element dynamic model coupling axial and torsional vibrations to study the effect of drillstring length variation on the drilling structure stability.

The axial vibrations can travel from the well bottom to the surface and have been studied by the analytical approach presented in [19]. The torsional vibrations, usually associated with the stick-slip phenomena of bit-rock and well-pipe contacts, was investigated by some simple models such as the wave equation [20], a dynamics system with one degree of freedom [21] or the continuous system approach [22]. Lateral vibrations (bending or flexural motions) are considered as the sources of structure failures and damages to the well. They have been studied since the mid $1960 \mathrm{~s}$ and extensively investigated by the finite element method since 1990s [23-25] thanks to computer development. However, the effects of the speed of rotation on the natural frequencies of drilling structure are not carefully studied. In the context of rotordynamics [26], the modal analysis usually decouples the lateral, torsional vibrations and computes the Campbell diagrams to determine the potential unstable speeds of rotation which may yield the harmful vibrations and resonances. Contrary to the classical rotors, the drill- 


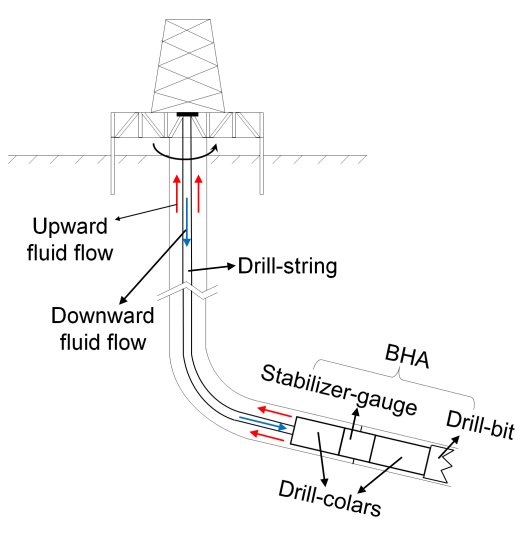

Fig. 1: Rotary drilling sketch.

string, also considered as a long rotor, shows a much more complicated dynamics, which represents the coupling phenomena between flexural, torsional and longitudinal vibrations. A few works investigated the Campbell diagrams of simple rotors immersed in fluids by some theoretical and experimental analysis [27-30].

Most of the models aforementioned are limited to some simple uniform drillstring and well geometries (vertical or horizontal) with uncomplete coupling phenomena of vibrations. This paper proposes a finite element model to compute the Campbell diagram of drilling structure in curved wells by using Timoshenko beams in the presence of fluid. Thanks to the beam element method, this model is able to consider a realistic geometry of drilling assembly in 3D wells and to give a complete study of coupling phenomena between axial, torsional and lateral vibrations. Section 2 presents the beam element formulation based on the rotordynamics presented in [26], the models of well-pipe contacts and the fluidstructure interactions. The algorithm of the computation of Campbell diagram is introduced in Section 3. The first step is to compute the static position of the structure in curved wells to identify the contact points and pre-loaded state. These results are then considered to compute the Campbell diagram. The reduction technique is applied to reduce the computational time. A criterion based on the relative kinetic and strain energy contribution is proposed to classify the vibration natures of modes in rotation. A mode shape tracking technique is implemented for tracking and plotting, versus the speeds of rotation, the eigen-frequencies having the similar mode shapes. Section 4 presents some simple academic test cases to study the influence of well-pipes contacts and of the fluid on the Campbell diagram. Section 5 considers one drilling assembly in 3D wells to analyze the effect of the speed of rotation on the modes in rotation. The potential unstable region and critical speeds of rotation are determined.

\section{Beam element formulation}

\subsection{Drilling structure}

The details of the beam element formulation of drilling structure are presented in [31]. As shown in Figure 2, the drilling structure is meshed along the axial curvilinear direc-

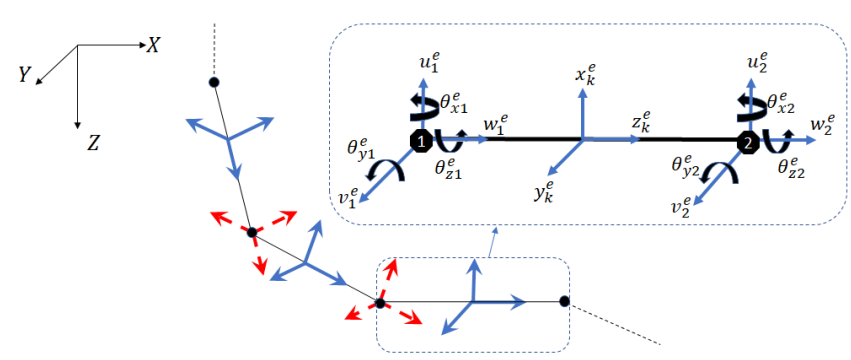

Fig. 2: Finite element mesh of drillstring. Solid vectors: elementary frame of reference, dashed vector: nodal frame of reference.

tion by a series of beam elements with two nodes per element. Each node is characterized by six degrees of freedom (dofs) including three displacements $(u, v, w)$, two lateral rotations $\left(\theta_{x}, \theta_{y}\right)$ and one torsional angle $\theta_{z}$.

The energies of one beam element are mainly due to the kinetic movements and the strain deformation. Let the elementary displacement vector containing the motions of two nodes be denoted: $\delta^{e}=$ $\left[u_{1}^{e}, v_{1}^{e}, w_{1}^{e}, \theta_{x 1}^{e}, \theta_{y 1}^{e}, \theta_{z 1}^{e}, u_{2}^{e}, v_{2}^{e}, w_{2}^{e}, \theta_{x 2}^{e}, \theta_{y 2}^{e}, \theta_{z 2}^{e}\right]^{T}$. By using six shape functions

$$
\begin{aligned}
& N_{1}(z)=1-\frac{3 z^{2}}{l^{2}}+\frac{2 z^{3}}{l^{3}}, N_{2}(z)=z-\frac{2 z^{2}}{l}+\frac{z^{3}}{l^{2}}, N_{3}(z)=\frac{3 z^{2}}{l^{2}}-\frac{2 z^{3}}{l^{3}} \\
& N_{4}(z)=-\frac{z^{2}}{l}+\frac{z^{3}}{l^{2}}, N_{5}(z)=1-\frac{z}{l}, N_{6}(z)=\frac{z}{l}
\end{aligned}
$$

with $l$ the element length, the finite element (FE) forms of elementary kinetic and strain energies are $E_{c a}^{e}=\frac{1}{2} \dot{\delta}^{e T} \mathbf{M}_{a}^{e} \dot{\delta}^{e}+$ $\delta^{e T}\left(\Omega \mathbf{C}_{a c}^{e}\right) \dot{\delta}^{e}$ and $E_{d a}^{e}=\frac{1}{2} \delta^{e T} \mathbf{K}_{a}^{e} \delta^{e}$ with $\mathbf{M}_{a}^{e}, \mathbf{K}_{a}^{e}$ the elementary mass and elastic stiffness matrices, $\mathbf{C}_{a c}^{e}$ related to the Coriolis effect of one beam element. Assembling all the beam elements gives the total energies $E_{c a}=\frac{1}{2} \dot{\delta}^{T} \mathbf{M}_{a} \dot{\delta}+$ $\delta^{T}\left(\Omega \mathbf{C}_{a c}\right) \dot{\delta}$ and $E_{d a}=\frac{1}{2} \delta^{T} \mathbf{K}_{a} \delta$ where $\Omega$ is the speed of rotation, $\mathbf{M}_{a}$ and $\mathbf{K}_{a}$ are the total mass and elastic stiffness matrices, $\mathbf{C}_{a c}$ represents the gyroscopic effect, $\delta$ and $\dot{\delta}$ store all displacements and velocities defined in the nodal reference frame. The reference frame of one node is the one of its left element. The Timoshenko beam are considered as in [26].

The elementary parametric axial force $F_{a}^{e}$ and torque $T_{a}^{e}$ induce stress stiffening, modelled respectively with two elementary geometric stiffness matrices $\mathbf{K}_{G F}^{e}, \mathbf{K}_{G T}^{e}$ and the global matrices $\mathbf{K}_{G F}, \mathbf{K}_{G T}$ [26]. The structural damping effects are characterized by the Rayleigh damping matrix with two coefficients $c_{M}, c_{K}: \mathbf{C}_{a d}=c_{M} \mathbf{M}_{a}+c_{K}\left(\mathbf{K}_{a}+\mathbf{K}_{G F}+\right.$ $\left.\mathbf{K}_{G T}\right)$.

\subsection{Well-drillstring contacts}

Due to the bending deflections, the mechanical contacts occur between the rotating beam and the well (see Figure 3). The well-pipes contacts are modeled by a series of radial 


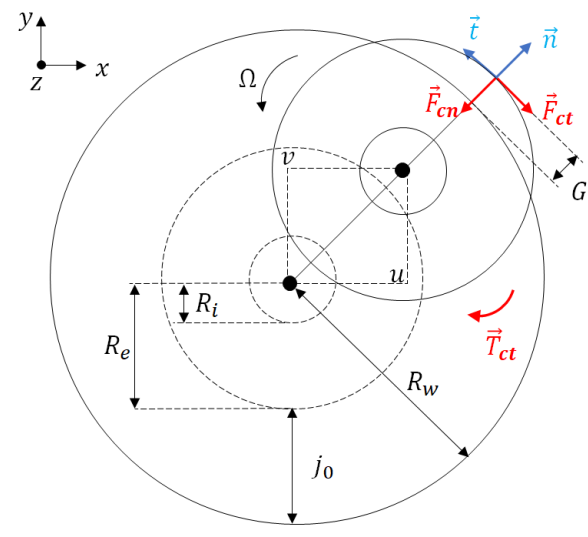

Fig. 3: Well-pipe contacts in the $x-y$ plane of nodal reference frame.

elastic stops. In the transverse $x-y$ plan of the reference frame of one contact node, the normal contact force is given by:

$$
\vec{F}_{c n}=-\left(K_{c}(G) G+C_{c}(G) \dot{G}\right) \vec{n}
$$

with $\vec{n}=u / r \vec{x}+v / r \vec{y}, G=r-j_{0}$ the penetration of beam cross-section in the well, $\dot{G}=(\dot{u} u+\dot{v} v) / r$ the penetration velocity, $r=\sqrt{u^{2}+v^{2}}$ the radial displacement and $j_{0}$ the radial clearance.

Instead of the classical contact law modeling two discontinuous states (contact or no contact) and leading to numerical problems, a contact law based on parameters $\lambda_{k}$ and $\lambda_{c}$ to regularize the stiffness and damping functions is chosen, see [32,33]: $K_{c}(G)=\frac{k_{c}}{2}\left[\frac{2}{\pi} \arctan \left(\pi \lambda_{k} G\right)+1\right]$ and $C_{c}(G)=\frac{c_{c}}{2}\left[\frac{2}{\pi} \arctan \left(\pi \lambda_{c} G\right)+1\right]$, with $k_{c}$ and $c_{c}$ the nominal contact stiffness and damping

The tangential friction force $\vec{F}_{c t}$ and torque $\vec{T}_{c t}$ (Figure 3) depend on the sliding velocity $v_{g}=(u \dot{v}-v \dot{u}) / r+(\Omega+$ $\left.\dot{\theta}_{z}\right) R_{e}$ [33]. They are modeled by the smoothed Coulomb law:

$$
\begin{array}{r}
\vec{F}_{c t}=-\mu\left(v_{g}\right)\left(K_{c}(G) G+C_{c}(G) \dot{G}\right) \vec{t}, \\
\vec{T}_{c t}=-\mu\left(v_{g}\right)\left(K_{c}(G) G+C_{c}(G) \dot{G}\right) R_{e} \vec{z},
\end{array}
$$

with $\vec{t}=-v / r \vec{x}+u / r \vec{y}$. The friction direction depends on the sign of the friction function $\mu\left(v_{g}\right)$. A regularized form of $\mu\left(v_{g}\right)$ based on the dynamic and static friction coefficients $\mu_{d}$, $\mu_{s}$ and on the regularized parameter $v_{r}$ is considered $[32,33]$

$$
\mu\left(v_{g}\right)=\frac{v_{g}}{2 v_{r}}\left(\frac{1-\xi}{1+\frac{1-\xi}{2 v_{r} \mu_{d}}\left|v_{g}\right|}+\frac{1+\xi}{\left(1+\frac{1-\xi}{2 v_{r} \mu_{d}}\left|v_{g}\right|\right)^{2}}\right)
$$

with $\xi=\sqrt{1-\mu_{d} / \mu_{s}}$.

\subsection{Fluid-drill-pipe interaction}

The inner fluid inside the hollow drilling structure induces the inertial force on the drilling assembly. The effects of the outer fluid in the annular space are characterized by inertial and friction forces developed in [27-30]. This model does not consider the fluid flow in the axial direction. The fluid is initially at rest and then entrained in the circumferential direction due to the rotation of drillstring. As shown in [27-30], this fluid significantly affects the flexural vibrations even for low speeds of rotation.

The viscosity effects are added to the dissipation matrix defined in the modal basis [28, 29] (see Section 3.2). The inertial and friction forces of the outer fluid are characterized by the add mass $m_{a}=\rho_{f} \pi R_{f i}^{2} \frac{R_{f i}^{2}+R_{f e}^{2}}{R_{f e}^{2}-R_{f i}^{2}}$ and $\gamma=$ $f_{f} \frac{R_{f e}+R_{f i}}{2\left(R_{f e}-R_{f i}\right)}$ with $R_{f e}, R_{f i}$ the outer and inner radii of the annular space, $\rho_{f}$ is the mass density of the outer fluid, $f_{f}$ the tangential friction coefficient.

By using the nodal interpolations by shape functions [31], the virtual work of the inertial and friction effects of outer fluid yields the FE forms: $\mathbf{F}_{i}^{e}=\mathbf{X}_{M}^{e} \ddot{\delta}^{e}+\Omega \mathbf{X}_{C}^{e} \dot{\delta}^{e}-$ $\frac{\Omega^{2}}{4} \mathbf{X}_{M}^{e} \delta^{e}$ and $\mathbf{F}_{f}^{e}=\gamma \Omega \mathbf{X}_{M}^{e} \dot{\delta}^{e}+\gamma \frac{\Omega^{2}}{2} \mathbf{X}_{C}^{e} \dot{\delta}^{e}$. The total effect of these forces is given by $\mathbf{F}_{f e}^{e}=\mathbf{M}_{f e}^{e} \ddot{\boldsymbol{\delta}}^{e}+\Omega \mathbf{C}_{f e}^{e} \dot{\boldsymbol{\delta}}^{e}+\Omega^{2} \mathbf{K}_{f e}^{e} \boldsymbol{\delta}^{e}$ where $\mathbf{M}_{f e}^{e}=\mathbf{X}_{M}^{e}, \mathbf{C}_{f e}^{e}=\mathbf{X}_{C}^{e}+\gamma \mathbf{X}_{M}^{e}, \mathbf{K}_{f e}^{e}=\frac{\gamma}{2} \mathbf{X}_{C}^{e}-\frac{\mathbf{X}_{M}^{e}}{4}$. The elementary inertial force of the inner fluid corresponds to $\mathbf{M}_{f i}^{e} \ddot{\boldsymbol{\delta}}^{e}$. The total fluid matrices $\mathbf{M}_{f e}, \mathbf{C}_{f e}, \mathbf{K}_{f e}$ and $\mathbf{M}_{f i}$ are obtained by assembling all fluid elements.

\section{Algorithm of the Campbell computation}

Figure 4 represents three steps for computing the Campbell diagram. The quasi-static equilibrium position is firstly computed by considering all exterior static loads, the static contact forces and torques. This step determines the preloaded state of the drilling assembly and the drillstring nodes in contact with the well. By assumption these nodes are considered in permanent contact for the Campbell diagram computation. Consequently, the Campbell calculation takes into account a stiffness matrix comprising the permanent contact stiffness, the drillstring stiffness with its stress stiffening due to 3D curvilinear trajectory and external static loads. The contact stiffness matrix $\mathbf{K}_{b}$ is then added to reduce the lateral displacements of these nodes. The pre-loaded state of structure from the static position are also considered by adding the geometric stiffness matrices $\mathbf{K}_{G F}$ and $\mathbf{K}_{G T}$ to the structure stiffness. These matrices are characterized by the elementary axial force $F_{a}^{e}=\frac{E S}{l}\left(w_{i+1}-w_{i}\right)$ and torque $T_{a}^{e}=\frac{E I_{p}}{2(1+\mathrm{v}) l}\left(\theta_{z, i+1}-\theta_{z, i}\right)$ where $w_{i}, w_{i+1}, \theta_{z, i}$ and $\theta_{z, i+1}$ are results of the static computation, $E$ denotes the Young modulus, $S$ is the beam cross-section and $I_{p}$ is the polar moment of inertia around the $z$-axis. The final step is to apply the reduction technique based on the modal basis to calculate the Campbell diagram. The following subsections present 


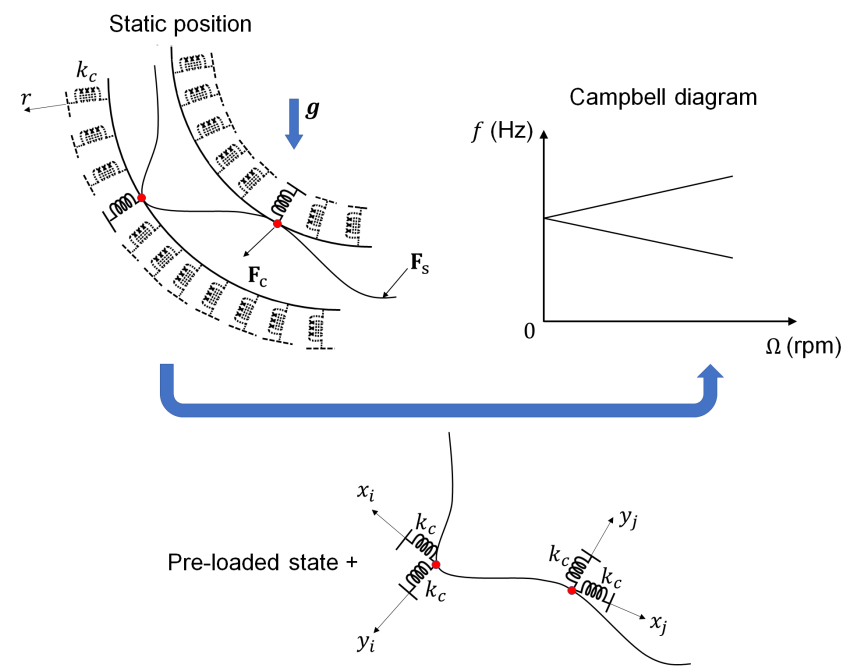

Fig. 4: Algorithm of the Campbell diagram computation.

each step in details.

\subsection{Static position}

The static equilibrium state of drilling structure in a well is governed by the nonlinear equation:

$$
\mathbf{K}_{a} \boldsymbol{\delta}=\mathbf{F}_{s}+\mathbf{F}_{c s}(\boldsymbol{\delta}),
$$

where $\mathbf{F}_{s}$ denotes all external static loads such as the gravity and buoyancy forces, the Weight-on-Bit (WOB) and the Torque-on-Bit (TOB). $\mathbf{F}_{c s}$ corresponds to the static contact forces and torques. Its normal component $\mathbf{F}_{c n s}$ is defined from Eqn. (2) by $\vec{F}_{c n s}=-K_{c}(G) G \vec{n}$.

Eqn. (5) describes the real static equilibrium if only the normal contact force is considered. When the structure rotates and has the permanent contact with the well, this situation corresponds to the "quasi"-static equilibrium. In this case, $\mathbf{F}_{c}$ contains also the static tangential friction forces $\mathbf{F}_{c t s}$ and torques $\mathbf{T}_{c t s}$ applied to each contact node obtained from Section 2.2: $\vec{F}_{c t s}=-\mu_{s} K_{c}(G) G \vec{t}, \vec{T}_{c t s}=-\mu_{s} K_{c}(G) G R_{e} \vec{z}$.

The Newton-Raphson method is applied to solve Eqn. (5) by an iterative loop:

a) Initial displacement vector $\delta_{0}$ is chosen as $\mathbf{K}_{a}^{-1} \mathbf{F}_{s}$.

b) The displacement vector $\delta_{i}$ at the $i^{\text {th }}$ iteration is assumed to be known, the increment correction is defined by :

$$
d \delta_{i}=-\left(\mathbf{K}_{a}-\left.\frac{\partial \mathbf{F}_{c s}}{\partial \delta}\right|_{\delta=\delta_{i}}\right)^{-1}\left(\mathbf{K}_{a} \boldsymbol{\delta}_{i}-\mathbf{F}_{s}-\mathbf{F}_{c s}\left(\boldsymbol{\delta}_{i}\right)\right)
$$

matrix:

$$
\mathbf{J}_{p}=\left(\begin{array}{cccccc}
\frac{\partial F_{c n s x}}{\partial u}+\frac{\partial F_{c t s x}}{\partial u} \frac{\partial F_{c n s x}}{\partial v}+\frac{\partial F_{c t s x}}{\partial v} & 0 & 0 & 0 & 0 \\
\frac{\partial F_{c n s y}}{\partial u}+\frac{\partial F_{c t s y}}{\partial u} \frac{\partial F_{c n s y}}{\partial v}+\frac{\partial F_{c t s y}}{\partial v} & 0 & 0 & 0 & 0 \\
0 & 0 & 0 & 0 & 0 & 0 \\
0 & 0 & 0 & 0 & 0 & 0 \\
0 & 0 & 0 & 0 & 0 & 0 \\
\frac{\partial T_{f t s}}{\partial u} & \frac{\partial T_{f t s}}{\partial v} & 0 & 0 & 0 & 0
\end{array}\right) .
$$

and

$$
\frac{\partial \mathbf{F}_{c s}}{\partial \delta}=\left(\begin{array}{ccccc}
\mathbf{J}_{1} & \mathbf{0} & \ldots & \mathbf{0} & \mathbf{0} \\
\mathbf{0} & \mathbf{J}_{2} & \ldots & \mathbf{0} & \mathbf{0} \\
\vdots & \vdots & \ddots & \vdots & \vdots \\
\mathbf{0} & \mathbf{0} & \ldots & \mathbf{J}_{P-1} & \mathbf{0} \\
\mathbf{0} & \mathbf{0} & \ldots & \mathbf{0} & \mathbf{J}_{P}
\end{array}\right)
$$

c) Applying the correction : $\delta_{i+1}=\delta_{i}+d \delta_{i}$.

d) If the relative error $\frac{\left\|d \delta_{i}\right\|_{2}}{\left\|\delta_{i+1}\right\|_{2}}$ is smaller than a criterion $\varepsilon_{0}$, the iterative loop is stopped. Otherwise, the process returns to step $b$ ).

\subsection{Campbell computation with the modal reduction}

The modes in rotation of a rotating system, $\delta_{k}=\mathbf{X}_{k} e^{r_{k} t}$, are solutions of the quadratic eigenproblem:

$$
\left(r_{k}^{2} \mathbf{M}+r_{k} \mathbf{C}+\mathbf{K}\right) \mathbf{X}_{k}=\mathbf{0}
$$

where $\mathbf{M}=\mathbf{M}_{a}+\mathbf{M}_{f i}+\mathbf{M}_{f e}, \mathbf{C}=\mathbf{C}_{a d}+\left(\mathbf{C}_{a c}^{T}-\mathbf{C}_{a c}+\mathbf{C}_{f e}\right) \Omega$ and $\mathbf{K}=\mathbf{K}_{a}+\mathbf{K}_{G F}+\mathbf{K}_{G T}+\mathbf{K}_{b}+\mathbf{K}_{f e} \Omega^{2}$.

By using the projection matrix $\Phi$ containing a few first modes of the modal basis defined in [31], the change of variable $\mathbf{X}=\Phi \mathbf{q}$ introduced in the energies and virtual works yields the modal equations:

$$
\left(r_{k}^{2} \mathbf{m}+r_{k} \mathbf{c}+\mathbf{k}\right) \mathbf{q}_{k}=\mathbf{0}
$$

with $\mathbf{m}=\Phi^{T} \mathbf{M} \Phi, \mathbf{k}=\Phi^{T} \mathbf{K} \Phi, \mathbf{c}=\Phi^{T} \mathbf{C} \Phi+\mathbf{c}_{\eta} . \quad \mathbf{c}_{\eta}$ is a diagonal matrix representing the modal viscous damping with the diagonal terms given by $[28,29]: \mathbf{c}_{\eta, j}=$ $\Phi_{j}^{T} \Phi_{j} \tilde{m}_{a} \sqrt{\frac{2 \tilde{\eta} \omega_{j}}{\left(\tilde{R}_{f e}-\tilde{R}_{f i}\right)^{2}}}$ where $\Phi_{j}$ and $\omega_{j}$ denote the eigenvectors and eigenvalues of the modal basis, $\tilde{m}_{a}=$ $\tilde{\rho}_{f} \pi \tilde{R}_{f i}^{2} \frac{\tilde{R}_{f i}^{2}+\tilde{R}_{f e}^{2}}{\tilde{R}_{f e}^{2}-\tilde{R}_{f i}^{2}} . \tilde{R}_{f e}, \tilde{R}_{f i}, \tilde{\eta}, \tilde{\rho}_{f}$ denote the mean values of $R_{f e}, R_{f i}, \eta, \rho_{f}$ for all cross-sections of well-drillstring annular spaces.

with $P$ the node number and $\mathbf{J}_{p, p=1 \ldots P}$ the nodal Jacobian 
The problem (10) is rewritten as a linear one. Due to the non-symmetric matrices $\mathbf{k}$ and $\mathbf{c}$, the eigenvalues are the complexes of the form $2 \pi(\alpha \pm j f)$. The positive values of $\alpha$ induce the unstable vibrations. The dependence of $f$ on the speed of rotation gives the Campbell diagram.

\subsection{Classification and mode shape tracking}

For better understanding the structure vibrations, the modes in rotation are classified by three categories of motion: (F) like-flexural, (T) like-torsional and (L) like-longitudinal modes. The classification criterion is based on three indicators:

$$
S_{i}=\frac{\sum_{e} E_{c i}^{e}}{\sum_{e, i} E_{c i}^{e}}+\frac{\sum_{e} E_{d i}^{e}}{\sum_{e, i} E_{d i}^{e}}, \quad i=\{F, T, L\}
$$

with $E_{c i}^{e}=\frac{1}{2}\left|\left(r \mathbf{X}_{i}^{e}\right)^{*} \mathbf{M}_{a i i}^{e}\left(r \mathbf{X}_{i}^{e}\right)\right|, E_{d i}^{e}=\frac{1}{2}\left|\mathbf{X}_{i}^{e *} \mathbf{K}_{a i i}^{e} \mathbf{X}_{i}^{e}\right|, *$ denoting the transposed conjugately operator. $\mathbf{X}_{i}^{e}, \mathbf{M}_{a i i}^{e}, \mathbf{K}_{a i i}^{e}$ denote the sub vector and matrices extracted from $\mathbf{X}^{e}, \mathbf{M}_{a}^{e}$, $\mathbf{K}_{a}^{e}$ of each beam element and correspond to the flexural, torsional or longitudinal dofs respectively. The first and second terms of $S_{i}$ correspond to the relative contribution of kinetic and strain energies. The maximal values of these terms and of $S_{i}$ are equal respectively to 1 and 2. A Campbell mode is considered as (F) if $S_{F}>S_{T}, S_{L}$, (T) if $S_{T}>S_{F}, S_{L}$, (L) if $S_{L}>S_{F}, S_{T}$.

For each speed of rotation step, the eigenmodes are numbered in the order of the increasing imaginary part of their eigenvalues. However, the mode shape associated with the $k^{\text {th }}$ eigenvalue at a speed of rotation may not correspond to the $k^{\text {th }}$ eigenvalue at the next speed, which makes difficult the continuous plot of the natural frequencies versus the speed of rotation.. This difficulty is overcomed by applying the $\mathrm{NC}^{2} \mathrm{O}$ mode shape tracking method [34].

\section{Academic test cases}

The objective of academic cases is to highlight the contact friction effects on static positions, the influence of fluid and of well-pipe contacts on the Campbell diagram. Although these test cases are more related to classical rotors than the drilling structure, the studies are to understand and illustrate the results obtained for the vibration analysis of real drilling assembly presented in the next section.

Let a horizontal uniform homogeneous rod of length $L=11 \mathrm{~m}$, similar to a drill-pipe, be discretized by 101 equidistant nodes and subjected to the gravity with $g=9.81$ $\mathrm{m} . \mathrm{s}^{-2}$. Its inner and outer radii are $0.04 \mathrm{~m}$ and $0.06 \mathrm{~m}$, respectively. The steel beam is characterized by the mass density $\rho=7860 \mathrm{~kg} \cdot \mathrm{m}^{-3}$, the Young modulus $E=2.110^{11} \mathrm{~Pa}$ and the Poisson ratio $v=0.3$. The two Rayleigh damping coefficients are $c_{M}=0.03 \mathrm{~s}^{-1}$ and $c_{K}=0 \mathrm{~s}$ [13]. The beam vibrations are studied in three cases sketched by Figure 5. In the case 1 , one radial elastic stop is present. In the case 2,
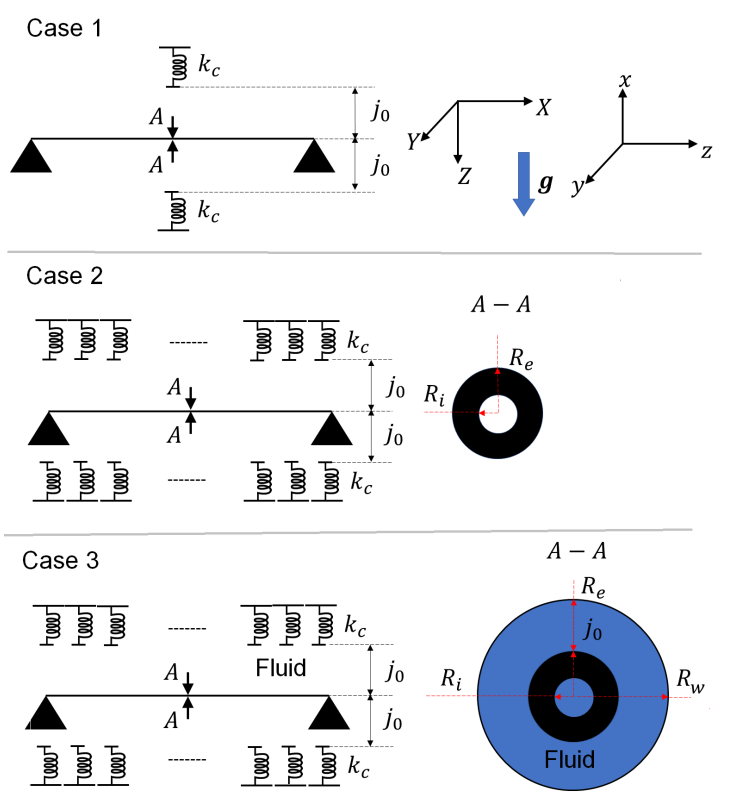

Fig. 5: Academic test cases. XYZ: Cartesian frame of reference with the gravity acceleration in the $Z$ direction, $x y z$ : nodal frame of reference.

many radial elastic stops are present to model the potential contact between the beam and the horizontal well. There is at each node, one radial elastic stop per node. The case 3 is the same as the case 2 but with the inner and outer fluids. The elastic stops have the nominal stiffness $k_{c}=10^{9}$ N.m ${ }^{-1}$ with the regularized parameter $\lambda_{k}=710^{9} \mathrm{~m}^{-1}$, the radial clearance $j_{0}=0.01 \mathrm{~m}$ and the static friction coefficient $\mu_{s}=0.2$. The inner and outer fluids have the rheological properties $\rho_{f}=1200 \mathrm{~kg} \cdot \mathrm{m}^{-3}, \eta=10^{-6} \mathrm{~m}^{2} \mathrm{~s}^{-1}$ and $f_{f}=0.02$ ou 0.05 .

The quasi-static and static positions of the beam, computed respectively with or without the contact friction effects, are plotted in Figure 6. The normal contact forces, the friction forces and torques are also shown at the contact nodes. Without the elastic stops, the bending at the center of simple supported beam is $5 \rho g S L^{4} /(384 E I) \simeq 0.054 \mathrm{~m}$. This bending is reduced to $0.01 \mathrm{~m}$ by the beam-elastic-stops contact. Considering only the normal contact force gives the displacement in $X-Z$ plane while the tangential friction force and torque induce the small out-of-plane displacements in the $Y$-direction. Case 1 represents only one contact at the center node. Cases 2, 3 show five contacts around the center node where the contact forces are maximal. Moreover, the comparison between Figures $6 \mathrm{~b}$ and $6 \mathrm{c}$ show that the fluid reduces the contacts between the beam and the elastic stops due to the buoyancy force.

The quasi-static results computed with the friction effects are considered to compute the Campbell diagrams. The reduction technique uses the first 8 modes of modal basis.

The Campbell diagrams are plotted in Figure 7. Following three indicators defined in Section $3.3\left(S_{F}=2, S_{T}=\right.$ $0, S_{L}=0$ ), only pure flexural modes are present in these cases. The solid curves represent the $\mathrm{NC}^{2} \mathrm{O}$ mode shape tracking. The orbits of lateral displacements of each mode 

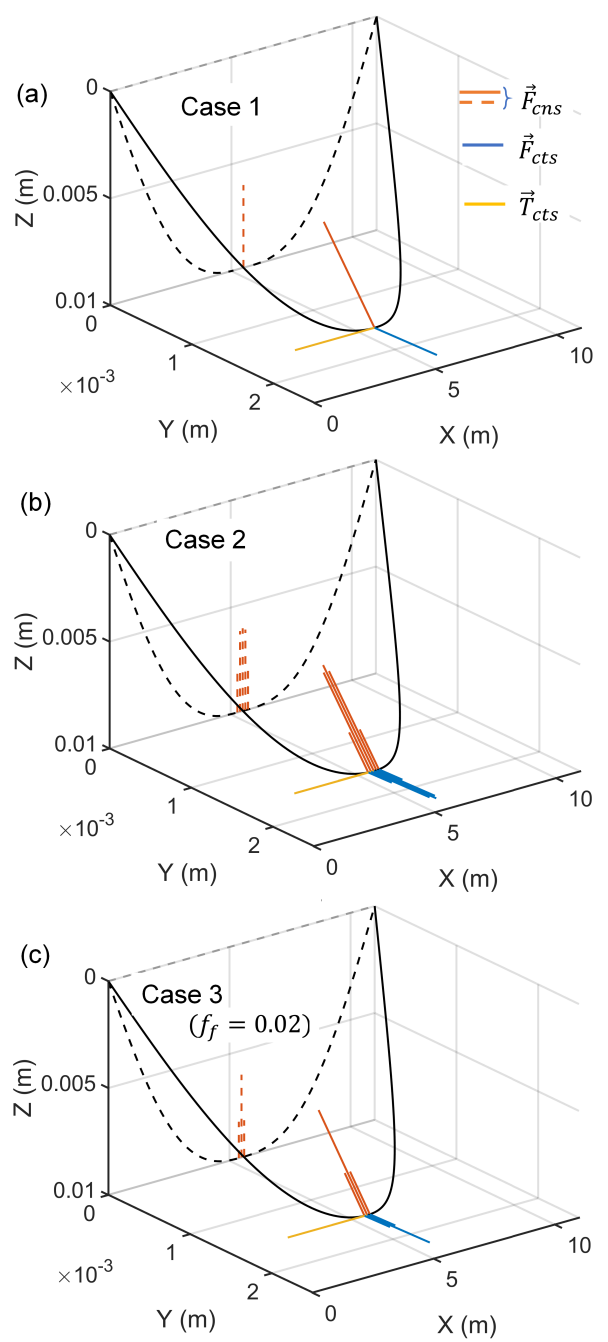

Fig. 6: Static (dashed curves) and quasi-static (continuous curves) positions with the contact forces and torques.

pair at $\Omega=250 \mathrm{rpm}$ are shown in Figure 8 . These mode pairs in rotation are numbered in the order of increasing frequencies.

The contact effects are studied by analyzing Figures 7 and 8 . For the case 2, the multi-contacts around the center node remove the mode pairs 1 and 3 of Case 1 whose displacements are zero only at the center node. The mode pairs 2, 4 of Case 1 still exist on the Campbell diagram of the case 2 and correspond to the mode pairs 1, 3 of Case 2 (see Figures $7 \mathrm{c}, 7 \mathrm{~d}, 8)$. New mode pairs 2, 4 of Case 2 appear, compared to the case 1 . In the case 2 , the frequencies of mode pairs 1 and 3 are very close to those of mode pairs 2 and 4 respectively. Only difference between their mode shapes is that the two half-beams rotate in the same phase for the mode pairs 1, 3 and in the opposite phase for the mode pairs 2, 4 (see the solid curves linking the circles in Figures 8).

The fluid effects are investigated by comparing Figures $7 \mathrm{~b}$ (Case 2) and 7c, 7d (Case 3). With the fluid, the unstable speeds of rotation exist from $\Omega=2000 \mathrm{rpm}$. Compared to the case 3 , the mode frequencies at $\Omega=0 \mathrm{rpm}$ decrease with the fluid presence. Moreover, the fluid makes the
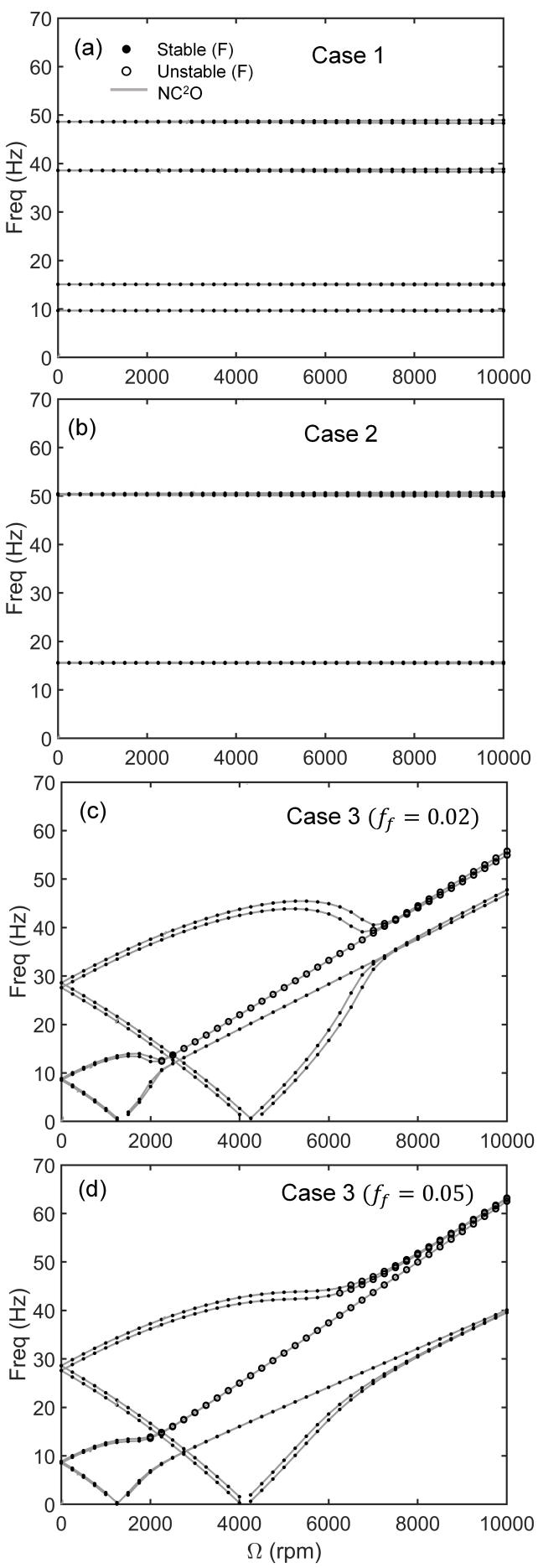

Fig. 7: Campbell diagrams of academic test cases.

(F) mode curves strongly deviated at the low speeds of rotation and then converged for the higher speeds of rotation. As mentioned in [29], the deviation of (F) mode curves almost depends on the fluid friction coefficient rather than the fluid viscosity. In fact, these curves are more deviated with a larger fluid friction coefficient (see Figures $7 \mathrm{c}$ and $7 \mathrm{~d}$ ). 

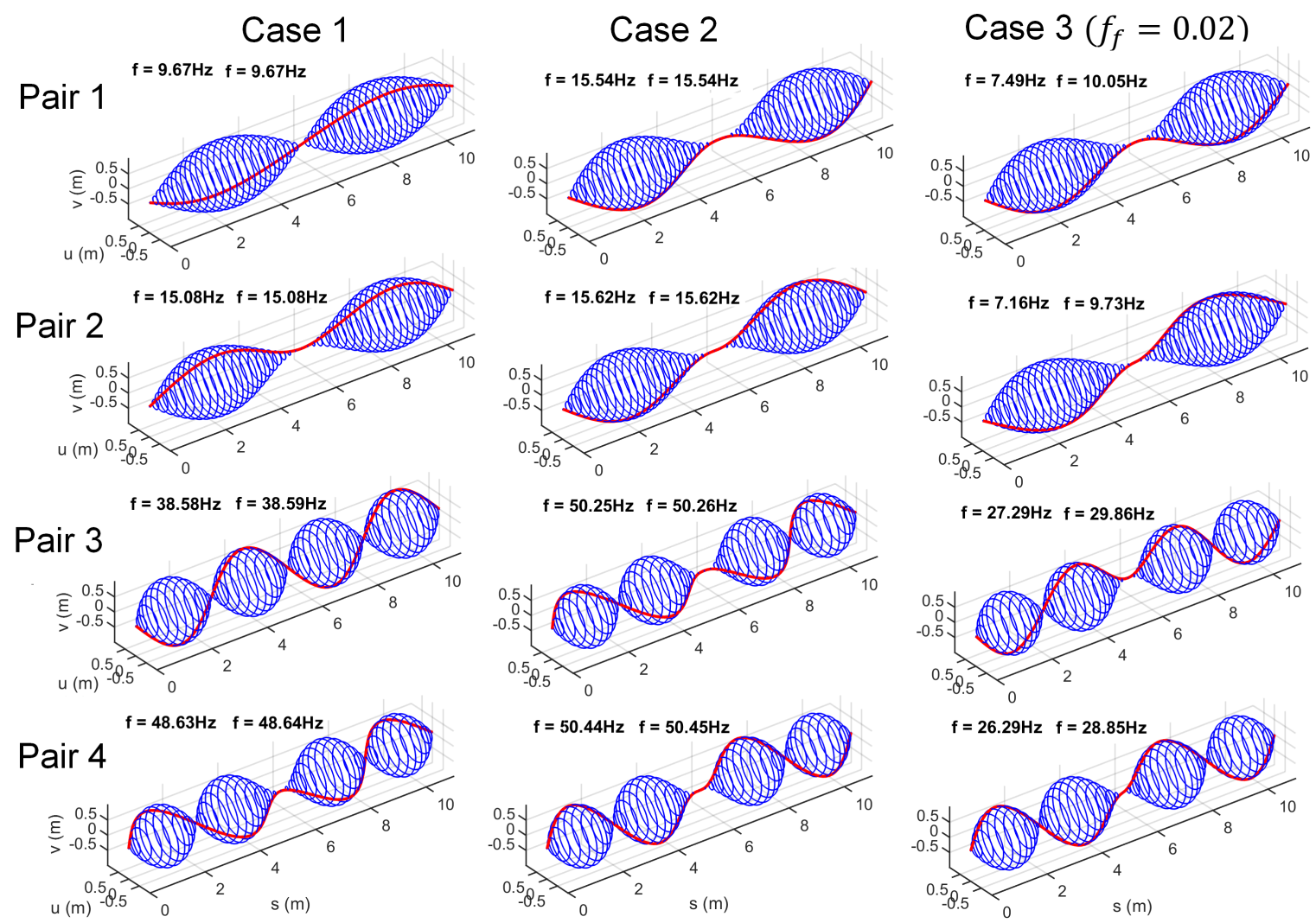

Fig. 8: Mode shape pairs in bending (F) for academic test cases at $\Omega=250 \mathrm{rpm}$. Solid curves: mode shape at $t=0 \mathrm{~s}$.

\begin{tabular}{lcll}
\hline Type & Length $(\mathrm{m})$ & $\begin{array}{l}\text { Outer } \\
\text { diameter }(\mathrm{m})\end{array}$ & $\begin{array}{l}\text { Inner } \\
\text { diameter }(\mathrm{m})\end{array}$ \\
\hline Drill-bit & 0.5 & - & - \\
Drill-collar & 10 & 0.159 & 0.071 \\
Stabilizer & 5 & 0.159 & 0.071 \\
Pipe-body & 8.9 & 0.127 & 0.108 \\
Tooljoint & 0.3 & 0.162 & 0.095 \\
\hline
\end{tabular}

\begin{tabular}{lcc}
\hline Type & Outer diameter $(\mathrm{m})$ & Inner diameter $(\mathrm{m})$ \\
\hline Casing 1 & 0.473 & 0.451 \\
Casing 2 & 0.244 & 0.222 \\
Openhole & 0.216 & 0.216 \\
\hline
\end{tabular}

Table 1: Geometric parameters of drilling structure.

\section{3D-well}

In this section, the drilling structure and the well geometry are close to the realistic configurations of drilling operations. The quasi-static position of structure is analyzed. The unstable speeds of rotation range and the critical speeds of rotation are identified from the Campbell diagram. The modal couplings are also studied.

Figure 9 represents all components of steel drilling structure of $2000 \mathrm{~m}$ length: a long series of drill-pipes beginning from the surface, some drill-collars, two stabilizers and one drill-bit at the well bottom. Three gauges applied at the stabilizers and the drill-bit to concentrate and guide the drilling direction. Table 1 summarizes the geometric parameters of the drilling components. The structural damping is characterized by two Rayleigh coefficients $c_{M}=0.03 \mathrm{~s}^{-1}$ and $c_{K}=0 \mathrm{~s}$ with the mass density $7860 \mathrm{~kg} \cdot \mathrm{m}^{-3}$, the Young

modulus $2.110^{11} \mathrm{~Pa}$ and the Poisson ratio 0.3.

Figure 10 shows a 3D well geometry. Table 2 gives the geometric parameters of three well parts whose diameters decrease from the surface. First $1300 \mathrm{~m}$ of the well length from the surface is equipped with two steel casings to protect the well bore. The well bottom is an openhole with only the rock wall. The static friction coefficients of steel structuresteel casing and rock openhole-steel casing contacts are set respectively to 0.2 and 0.3 since the rock-steel impacts represent more friction effects than the steel-steel impacts.

The fluid is present inside the structure and in the wellpipes annular space with the mass density $1200 \mathrm{~kg} \cdot \mathrm{m}^{-3}$, the tangential friction coefficient 0.013 and the kinematic viscosity coefficient $\eta=10^{-6} \mathrm{~m}^{2} . \mathrm{s}^{-1}$.

The drillstring is discretized by 1811 beam elements. The well-pipes contacts are modeled by the radial elastic stops characterized by $k_{c}=10^{9} \mathrm{~N} \cdot \mathrm{m}^{-1}$ and $\lambda_{k}=710^{9} \mathrm{~m}^{-1}$ (see Section 2.2). Table 3 gathers different clearances $j_{0}$ of the well-pipes annular space. The change of the pipes and 


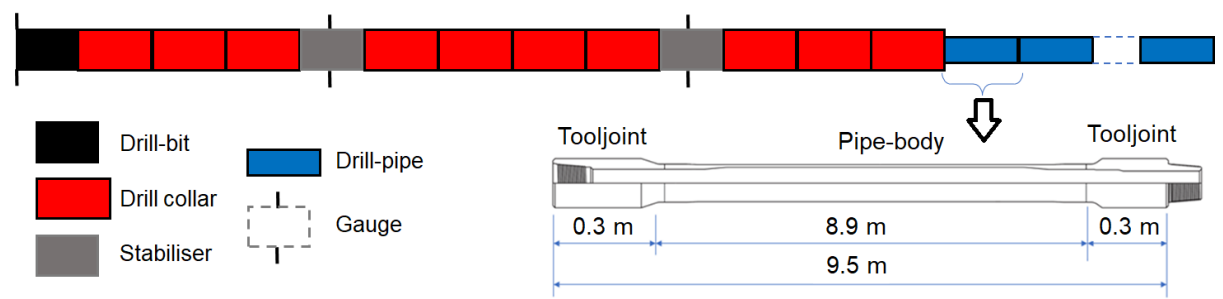

Fig. 9: Geometry of the drilling structure.

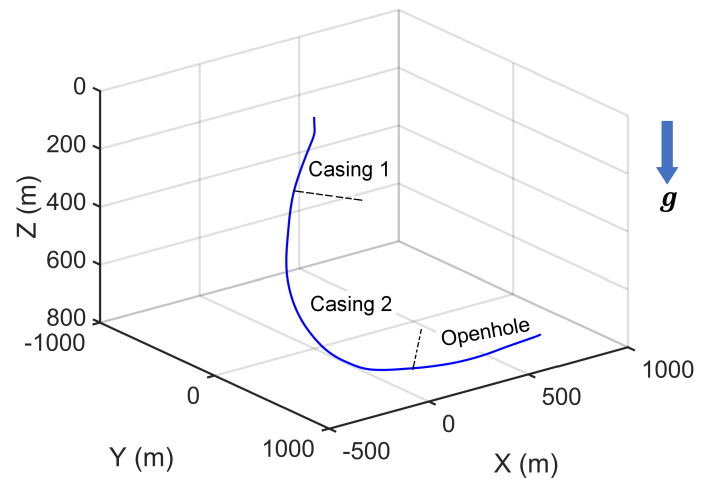

Fig. 10: 3D well geometry. Gravity force along the $Z$ axis.

\begin{tabular}{lc}
\hline Contact & Radial clearances (m) \\
\hline Pipe-body - casing 1 & 0.163 \\
Pipe-body - casing 2 & 0.048 \\
Pipe-body - openhole & 0.045 \\
Stabilizer - openhole & 0.029 \\
Drill-collar - openhole & 0.029 \\
Tooljoint - casing 1 & 0.145 \\
Tooljoint - casing 2 & 0.030 \\
Tooljoint - openhole & 0.027 \\
\hline
\end{tabular}

Table 3: Different clearances of well-pipes contacts.

well cross-sections is modeled by introducing supplementary clearances: $0.031 \mathrm{~m}, 0.144 \mathrm{~m}$. A very small clearance is considered between three in-gauges and the well.

Radial displacements of the quasi-static position of the drilling structure are represented in Figure 11. The grey points represent the clearances of different elastic stops. The nodal deflections $u$ and $v$ defined in Figure 3 are limited in the radial clearances due to the well-pipes contacts. The insets of Figure 11 represent the zooms of three regions in the casing 1 , casing 2 and openhole. The well-drillstring contacts occur at the tooljoints and the center of drill-pipes. Many nodes of drill-collars, gauges and drill-bit of BHA contact the openhole due to their heavy weight. Following Figure 12, the well-pipe contacts are the most important at the positions close to the surface $(Z \simeq 50 \mathrm{~m})$ and to the drill-bit $(Z \simeq 800$ $\mathrm{m})$.

The distribution of axial force $F_{a}^{e}$ and torque $T_{a}^{e}$ of each

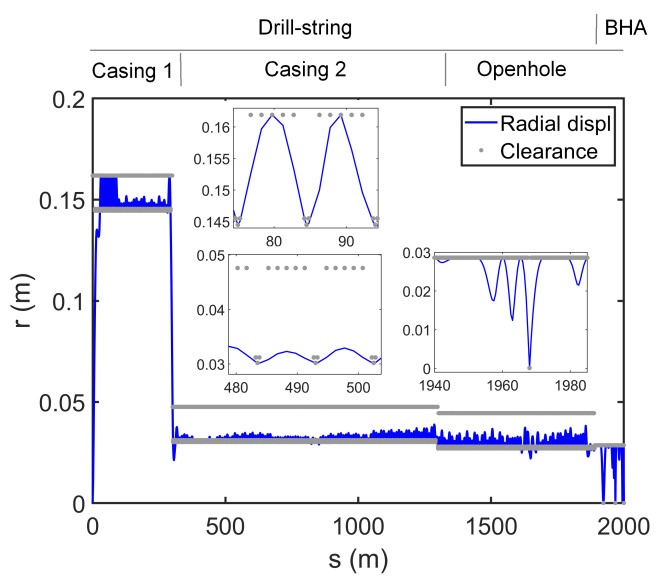

Fig. 11: Radial displacements of the drilling structure in 3D well as a function of the curvilinear position.

element computed as in Section 3 is represented in Figure 13. The axial force increases for the beam elements far away from the drill-bit. Its positive and negative values represent respectively the tension and compression states of the beam element. The first 700 elements close to the surface are in the tension state due to the steep trajectory and the remaining parts are compressed with the value approximately equal to the TOB at the bit due to the horizontal geometry at the well end. Figure 14 represents the elementary axial torque $T_{a}^{e}$ and the magnitude of nodal static friction torque $\left|\vec{T}_{c t s}\right|$ versus the curvilinear position. Following the zoom inset, the multi-jumps of $T_{a}^{e}$ between two adjacent elements occur when the common node of these elements is in contact with the well. The variations of $T_{a}^{e}$ for other non-contact parts of the drillstring are due to the well curvature.

The Campbell diagram plotted in Figure 15 is computed by using the first 10 modes of the modal basis. The long drillstring induces low natural frequencies. The discrete points of the diagram correspond to the (F), (T) and (L) modes. The diagram is clearly observed thanks to solid curves obtained by the $\mathrm{NC}^{2} \mathrm{O}$ mode shape tracking method (see Section 3.3 and Ref. [34]). The unstable ranges of rotary speeds exist for some (F) modes from $\Omega=280 \mathrm{rpm}$. The intersection between the mode curves and the critical line (dashed line) gives the potential critical speeds of rotation about $32 \mathrm{rpm}$, $34 \mathrm{rpm}, 63 \mathrm{rpm}, 63.5 \mathrm{rpm}, 83.5 \mathrm{rpm}$ etc. These speeds may yield the harmful resonances due to the external excitation such as the mass-unbalanced, asynchronous and eccentric forces [26]. 


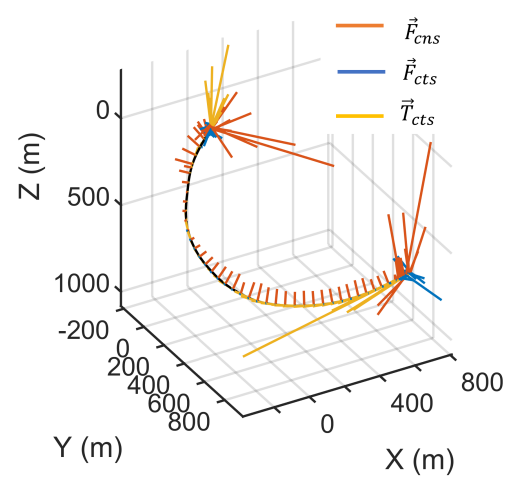

Fig. 12: Contact forces and torques applied to the drilling structure in 3D well.

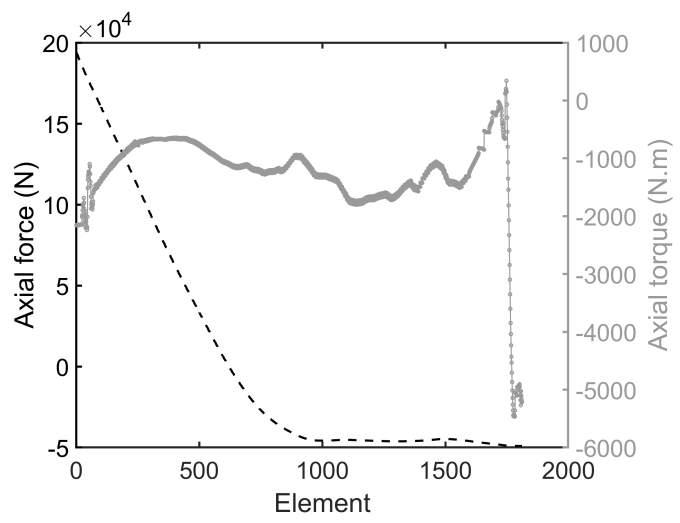

Fig. 13: Elementary axial force $F_{a}^{e}$ (dashed curves) and torque $T_{a}^{e}$ (solid curves) from the quasi-static positions in 3D well.

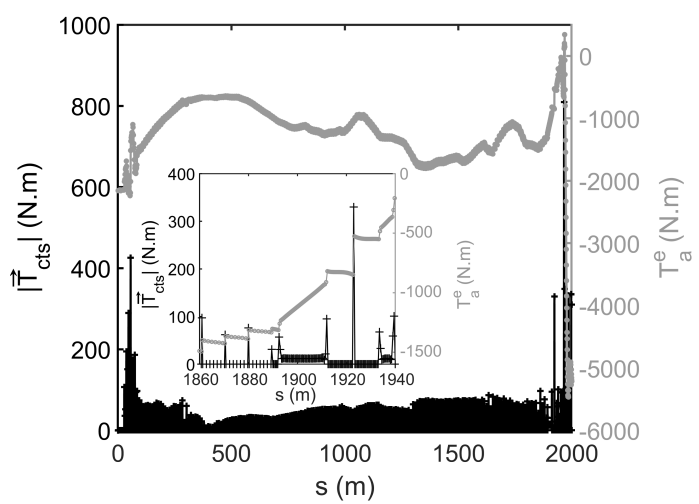

Fig. 14: Elementary axial torque $T_{a}^{e}$ (gray curves), nodal static contact torque $\left|\vec{T}_{c t s}\right|$ (black curves) as a function of a curvilinear position with their zoom inset.

\begin{tabular}{cccccc}
\hline$\Omega(\mathrm{rpm})$ & Mode & $f(\mathrm{~Hz})$ & $S_{F}$ & $S_{T}$ & $S_{L}$ \\
\hline 100 & $\mathrm{~A}$ & 0.931 & 1.989 & 0.006 & 0.005 \\
100 & $\mathrm{~B}$ & 1.531 & 1.996 & 0.000 & 0.004 \\
100 & $\mathrm{C} 1$ & 0.524 & 0.995 & 0.000 & 1.005 \\
180 & $\mathrm{C} 2$ & 0.523 & 1.002 & 0.000 & 0.998 \\
\hline
\end{tabular}

Table 4: Indicators of some modes in Figure 15.

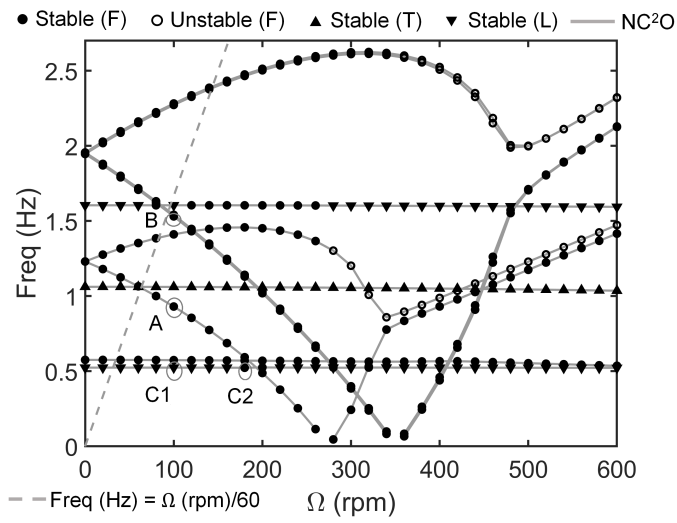

Fig. 15: Campbell diagram of the drilling structure in 3D well.

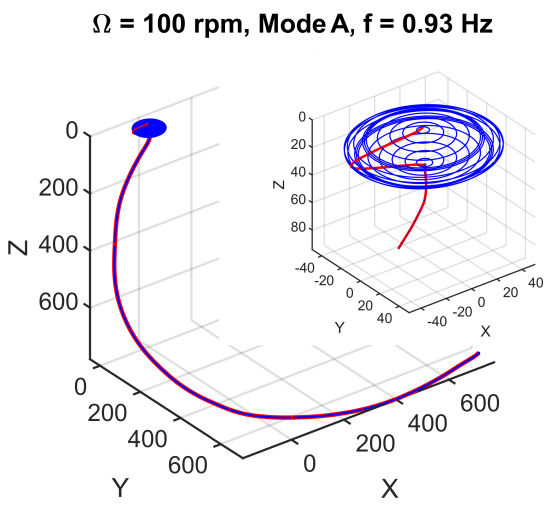

$\Omega=100 \mathrm{rpm}$, Mode $B, \mathrm{f}=1.53 \mathrm{~Hz}$

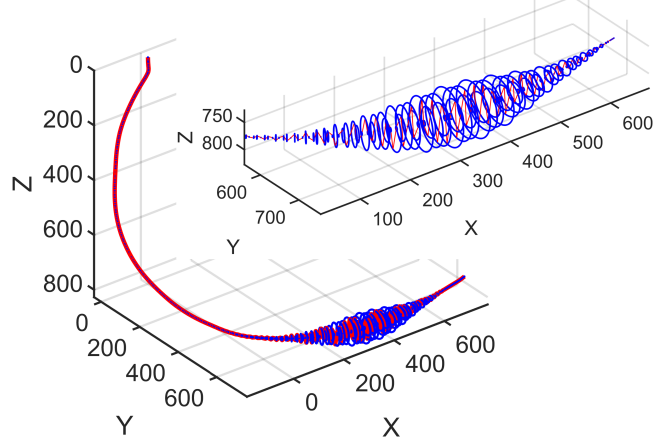

Fig. 16: Some (F) mode shapes of the drilling assembly in 3D well.

Similarly to the cases in Section 4 and in [29], the deviation of the Campbell curves of some $(\mathrm{F})$ mode pairs are observed and mainly due to the fluid friction. Contrary to $(\mathrm{F})$ modes, the frequencies of $(\mathrm{T})$ and $(\mathrm{L})$ modes are less dependent on the speeds of rotation.

Figure 16 represents mode shapes in rotation of $(\mathrm{F})$ modes having deviated curves. They show large circular orbits at the regions close to the surface and to the horizontal part of well.

Table 4 represents three indicators of some modes which are labeled by A, B, C1 and C2 in Figure 15. The modes A and $\mathrm{B}$ show a low coupling between flexural, torsional and 
longitudinal vibrations since $S_{F}$ is close to the maximal value 2 and $S_{T}, S_{L}$ are not zero. A strong flexural-longitudinal coupling can be observed for the modes $\mathrm{C} 1$ and $\mathrm{C} 2$ since their coefficients $S_{F}$ and $S_{L}$ are almost equal. The modes C1 and $\mathrm{C} 2$ are related to the same mode shapes with the vibration contribution changing versus speeds of rotation. In fact, the longitudinal vibration contribution of this mode shape is slightly stronger than the flexural one for almost all speeds of rotation, except for $\Omega \simeq 180 \mathrm{rpm}$ and $325 \mathrm{rpm}$.

\section{Conclusions}

The friction contact effects on the static position and on the elementary axial force and torque are studied for different test cases. The Campbell diagram is then computed over a large range of speeds of rotation by taking into account the pre-loaded structure and by assuming that the static contact nodes remain in the permanent contact with the well. The latter assumption permits the modes in rotation calculation with the lateral displacements of static contact nodes limited by adding the contact stiffness. The fluid friction effects induce the deviation of some $(\mathrm{F})$ mode curves. The potential unstable speeds of rotation are identified for the $3 \mathrm{D}$ realistic case. Contrary to a strong deviation of $(F)$ mode curves, the fluid effects on the (L) and (T) mode curves are negligible. The modal coupling mechanisms can be observed for a 3D well.

Compared to the time-domain computation of nonlinear dynamics of large drilling systems, the computation of Campbell diagram is much more simple and faster. The diagram analysis yields the interesting results of drilling vibrations such as the critical and unstable speeds of rotation which may induce the potentially dangerous vibrations or resonances.

\section{Acknowledgements}

The authors are indebted to the Agence Nationale de la Recherche (ANR) for its financial support. In the framework of the LaBCoM-SME program of ANR 15-LCV4-0010-01, this research is conducted by Drillab, a joint laboratory of DrillScan and INSA Lyon LaMCoS.

\section{References}

[1] Spanos, P., Chevallier, A., Politis, N., and Payne, M., 2003. "Oil well drilling: A vibrations perspective". The Shock and Vibration Digest, 35(2), pp. 81-99.

[2] Melakhessou, H., Berlioz, A., and Ferraris, G., 2003. "A nonlinear well-drillstring interaction model". Journal of Vibration and Acoustics-Transactions of the ASME, 125(1), pp. 46-52.

[3] Dunayevsky, V., Abbassian, F., and Judzis, A., 1993. "Dynamic stability of drillstrings under fluctuating weight on bit". SPE Drilling and Completion, 8(2), pp. 84-92.

[4] Dufeyte, M., and Henneuse, H., 1991. "SPE/IADC Drilling Conference, Amsterdam". In Detection and
Monitoring of the SlipStick Motion: Field Experiments, Vol. 21945, pp. 429-437.

[5] Macdonald, K., 1994. "Failure analysis of drillstring and bottom hole assembly components". Engineering Failure Analysis, 1(2), pp. 91-117.

[6] Christoufou, A. P., and Yigit, A. S., 1997. "Dynamic modelling of rotating drillstrings with borhole interactions". Journal of Sound and Vibration, 206(2), pp. 243-260.

[7] Ritto, T. G., Soize, C., and Sampaio, R., 2009. "Nonlinear dynamics of a drill-string with uncertain model of the bitrock interaction". International Journal of Non-Linear Mechanics, 44, pp. 865-876.

[8] Liu, X., Vlajic, N., Long, X., Meng, G., and Balachandran, B., 2014). "Coupled axial-torsional dynamics in rotary drilling with state-dependent delay: stability and control". Nonlinear Dynamics, 78, pp. 1891-1906.

[9] Gupta, S. K., and Wahi, P., 2016. "Global axialtorsional dynamics during rotary drilling”. Journal of Sound and Vibration, 375, pp. 332-352.

[10] Wiercigroch, M., Nandakumar, K., Pei, L., Kapitaniak, M., and Vaziri, V., 2017. "State dependent delayed drill-string vibration: Theory, experiments and new model". Procedia IUTAM, 22, pp. 39-50.

[11] Kreuzer, E., and Struck, H., 2003. "Mechanical modelling of drill-strings". Proc. Appl. Math. Mech., 3, pp. 88-91.

[12] Liao, C.-M., Balachandran, B., Karkoub, M., and Abdel-Magid, Y., 2011). "Drill-string dynamics: Reduced-order models and experimental studies". Journal of Vibration and Acoustics-Transactions of the ASME, 133(4), p. 041008.

[13] Cunha Jr, A., Soize, C., and Sampaio, R., 2015. "Computational modeling of the nonlinear stochastic dynamics of horizontal drillstrings". Computational Mechanics, 56(5), pp. 849-878.

[14] Wilson, J. K., 2017. "Nonlinear drillstring modeling with applications to induced vibrations in unconventional horizontal wells". PhD thesis, Texas A\&M University.

[15] Ezzeddine, D., 2013. "Modélisation du comportement dynamique d'un train de tiges de forage pétrolier : Application aux vibrations latérales". PhD thesis, École Nationale Supérieur des Mines de Paris.

[16] Feng, T., Kim, I., and Chen, D., 2018. "Dynamic modeling of directional drillstring: A linearized model considering well profile". Journal of Dynamic Systems, Measurement, and Control, 140(6), p. 061005.

[17] Hu, L., Palazzolo, A., and Karkoub, M., 2016). "Suppression of lateral and torsional stickslip vibrations of drillstrings with impact and torsional dampers". Journal of Vibration and Acoustics-Transactions of the ASME, 138(5), p. 051013.

[18] Hosseinzadeh, A., and Bakhtiari-Nejad, F., 2017). "A new dynamic model of coupled axial-torsional vibration of a drill string for investigation on the length increment effect on stickslip instability". Journal of Vibration and Acoustics-Transactions of the ASME, 
139(6), p. 061016.

[19] Dareing, D., and Livesay, B., 1968. "Longitudinal and angular drill-string vibrations with damping". Journal of Engineering for Industry, Transactions of the ASME, 90(4), pp. 671-679.

[20] Bailey, J., and Finnie, I., 1960. "An analytical study of drillstring vibration". Journal of Engineering for Industry, Transactions of the ASME, 82(2), pp. 122-128.

[21] Dawson, R., and Lin, Y.Q. andSpanos, P., 1987. "Drill string stickslip oscillations". In Proceedings of the 1987 Conference of the Society of Experimental Mechanics, Houston, TX, pp. 590-595.

[22] Brett, J., 1992. "The genesis of torsional drillstring vibrations". SPE Drilling Engineering, 7(3), pp. 168174.

[23] Vaz, M., and Patel, M., 1995. "Analysis of drill strings in vertical and deviated holes using the Galerkin method". Engineering Structures, 17(6), pp. 437-442.

[24] Dufour, R., and Berlioz, A., 1998. "Parametric instability of a beam due to axial excitations and to boundary conditions". Journal of Vibration and AcousticsTransactions of the ASME, 120(2), pp. 461-467.

[25] Berlioz, A., Hagopian, J. D., Dufour, R., and Draoui, E., 1996. "Dynamic behavior of a drill-string: Experimental investigation of lateral instabilities". Journal of Vibration and Acoustics-Transactions of the ASME, 118(3), pp. 292-298.

[26] Lalanne, M., and Ferraris, G., 1998. Rotordynamics Prediction in Engineering. Second edition. Wiley.

[27] Fritz, R. J., 1970. "The effects of an annular fluid on the vibration of a long rotor, part 1 - theory". Journal of Basic Engineering, ASME, 92(4), pp. 923-929.

[28] Chen, S. S., 1981. "Fluid damping for circular cylindrical structures". Nuclear Engineering and Design, 63(1), pp. 81-100.

[29] Axisa, F., and Antunes, J., 1992. "Flexural vibrations of rotors immersed in dense fluids. part I: Theory". Journal of Fluids and Structures, 6(1), pp. 3-21.

[30] Antunes, J., Axisa, F., and Hareux, F., 1992. "Flexural vibrations of rotors immersed in dense fluids. part II: Experiments". Journal of Fluids and Structures, 6(1), pp. 23-38.

[31] Nguyen, K.-L., Tran, Q.-T., Andrianoely, M.-A., Manin, L., Dufour, R., and Menand, S., 2019. A Rotordynamics Model for Rotary Drillstring with Nonlinear Interactions in a 3D Well., Vol. 62 of Mechanisms and Machine Science. Springer Netherlands.

[32] Duran, C., Manin, L., Andrianoely, M.-A., Bordegaray, C., and Dufour, R., 2012. "An analysis of rotor-stator interaction". In IMechE VIRM10 September 11-13, London.

[33] Duran, C., Manin, L., Andrianoely, M.-A., Bordegaray, C., Battle, F., and Dufour, R., 2014. "Effect of rotorstator contact on the mass unbalance response". In 9th IFToMM International Conference on Rotor Dynamics, September 22-25, Milano, Italy, pp. 1965-1975.

[34] Mogenier, G., Baranger, T., Ferraris, G., Dufour, R., and Durantay, L., 2012. "A criterion for mode shape tracking: application to Campbell diagrams". Journal of Vibration and Control, 20(2), pp. 179-190. 